presented by Major Wood; a Two-spotted Paradoxures (Nandinia binotata) from West $A$ frica, presented by Capt. E. J. Hawes; a Black-backed Jackal (Canis mesomelas) from South Africa, presented by Mr. Richard Seyd, F.Z.S. ; a Toque Monkey (Macacus pilcalus) from Ceylon, presented by Master R. C. Heyworth; a Bonelli's Eagle (Nisaetus fasciatus), European, presented by Lord Lilford, F.Z.S.; a Leadbeater's Cockatoo (Cacatua lead. beateri) from Australia, presented by Mrs. Tennent; a Goffin's Cockatoo (Cacatua goffini) from Queensland, presented by Mrs. Pitt; a White-backed Piping Crow (Gymnorhina leuconota) from Australia, presented by Mr. John Ritchie; three Water Ouzels (Cinclus aquaticus), European, presented by Mr. R. J. L. Price, F.Z.S.; a Slow Loris (Nyctictbus tardigradus) from Malacca, received in exchange; a Darwin's Pucras Pheasant (Pucrasia ditrvini), a Wonga-wonga Pigeon (Leucosarcia picata), nine Chilian Pintails (Dafila spinicauda), bred, a Reindeer (Ranifer arandus), born, in the Gardens.

\section{ACADEMIC LIBERTY IN GERMAN UNIVERSITIES ${ }^{1}$}

THIS liberty without control is a subject of astonishment to most strangers who know it only by certain very apparent eccentricities. They cannot understand how we are able, without great inconveniences, to leave young people to themselves in this way. The German remembers the student-period as the golden age of his life; our literature and our poetry are filled with the expression of this sentiment. We do not encounter anything similar to it among other European peoples. The German student is the only one who tastes an unmingled joy at the time when, in the first delight of his young independence, yet free from the anxieties of mercenary work, he may consecrate his hours cxclu ively to all that is noblest and best in science and in the conceptions of humanity. United by a friendly rivalry with numerous comrades devoted to the same efforts, he finds himself daily in intellectual communication with masters from whom he Learns what is the movement of thought among independent spirits. I appreciate at its full value this last advantage, when, looking back, I recall my student days and the impression made upon us by a man like Johannes Miiller, the physiologist. When one fixds himself in contact with a man of the first order, the entire scale of his intellectual conceptions is modified for life; contact with such a man is perhaps the most interesting thing which life may have to offer.

You possess, my young friend: in this liberty of German students, a precious and glorious legacy of past generations. Preserve it in order that ysu may leave it in your turn to those who will come after you, and strive to ennoble and purify it still more. To guard it intact you have, each for himself, to see that the studious youth of Gerinany continue worthy of the confidence which has secured for them so high a degree of liberty. There is here for feeble characters a gift as calamitous as it is precicus for the strong. Do not be astonished that statesmen and fathers of familie; think sometimes of instituting among us a systein of surveillance and control analogous to that which exists in England. There is no doubt that such a system would save many whom liberty allows to run to ruin. But the State and the nation have more to expect from those who are capable of supporting liberty and whose efforts and work are the results of their own individual encr $y$, of their dominion over themselves, and their love of science.

I have spoken above of the influence which may be exercised by intellectual contact with remarkable men; this leads me to point out another characteristic feature which distinguishes Germen universities from those of England and France. With us the student goes, as soon as posible, to seek instruction from masters who have proved their merit by doing something for the progress of science, which, in our eyes, is the best mark of their fitnoss to educate. Yet this is a thing which excites great astonishment among the English and French. They attach more importance than the Germans to a pretended talent for instruction, which consists in the faculty of expounding the subject of instruction in a clear and well-ordered form, and, if possible, in an eloquent and interesting manner, calculated to

'Rectorial Address of Prof. Helmh ltz, F.R.S., at the University of Berlir. Continued from p. 53. captivate the attention. At the Collége de France, the Jardin des Plantes, as also at Oxford and Cambridge, the lectures of renowned speakers are the rendezvous of the fashionable and cultivated world. In Germany we are not only indifferent to the oratorical apparatus, we are hostile to it; we undoubtedly neglect too much the external form. There is no doubt that a good exposition demands from the listener much less sustained efforts than a bad one ; it enables the subject to be comprehended much more surely and much more completely, and with a well. ordered arrangement, bringing into strong relief the principal points and the divisions, much more can be overtaken in the same space of time. I do not pretend, then, to justify the contempt of form, which we often push too far, both in speaking and in writing. But it cannot be denied that many men of great intellectual originality and of remarkable scientific value, have a dull, painful, and embarrassed elocution. Yet I have often seen such professors attract numerous and faithful hearers, while orators void of thought astonished at their first lecture, fatigued at the second, and were deserted at the third. He who wishes to inspire his audience with a complete conviction of the truth of what he advances, ought, above all, to know from personal experience what produces conviction. It is necessary then that he has known how to advance alone into a region where no one has ever broken ground; in other words he must have worked upon the frontiers of human science and conquered for himself new domains. A master who presents only results acquired by others suffices for scholars to whom authority is given as the source of their science, but not for those who desire to deepen their convictions to their final foundations.

There is here, you see, gentlemen, a new sign of confidence given you by the nation. There are neither fixed courses nor fixed professions imposed upon you. You are treated as men whose free adhesion must be gained, who know how to distinguish between being and seeming, whom it is no longer sought to persuade by appealing to any authority whatever, and who, moreover, would not allow themselves to be persuaded in that fashion. It is sought, more and more, to provide you with the means of drinking science at the very fountain, either in books and historical collections, or by observation of objects and natural pheomena and by experiments. The smallest German universi ties have their own libraries, their mineralogical collections, \&c. As regards the organisation of laboratories of chemistry, micrography, physiology, physics, Germany is ahead of all other European countries, who are only just beginning to seek to rival us. In our own university, we shall assist in a few weeks at the opening of two important establishments devoted to education in the natural sciences.

To obtain the free conviction of the pupils, it is necessary that the conviction of the masters be frcely expressed ; liberty of cducation is demanded. That has not always been protected from all encroachment in Germany more than in neighbouring countries. In times of political and religious strife the dominant parties have often interfered in the domain of science; but the German nation has always regarded such interferences as encroachments upon sacred ground. Here, again, the progress of political liberty in the new German Empire has been salutary. To-day, in the German universities, the most extreme results of materialistic metaphysics, the most daring speculations in the direction of the Darwinian theory of evolution, may be published without hindrance, as well as the most complete deification of the infallible Pope. No more than on the floor of European parliaments is it permitted to calumniate the intentions and out rage the person of an opponent-these are proceedings which have nothing to do with the discussion of a scientific proposition. It is also forbidden to excite to the commission of acts interdicted by the laws; but we may, without the least hindrance, discuss scientifically any controverted scientific point whatever. Liberty of education, in this sense, does not exist in the English and French universities. At the Collérge de France, even a man of so high a scientific reputation as Ernest Renan has been placed under interdict. The tutors of the English universitie may not diverge by a hair's breadth from the dogmatic system of the Anglican Church without exposing themselves to the censure of the archbishops and losing their pupils.

It remains for me to consider our liberty of education in another aspect. I wish to speak of the liberality with which our universities award the authority of professor.

In the etymological sense of the term, a doctor is a man $z i / h$ teaches, or at least, a man recognised as capable of teaching. In the universities of the middle age:, every doctor who found 
pupils, might be constituted master. In the course of time the practical signification of this title has been altered. Most of those who obtain it do not propose to teach; this title is only useful to them as a public mark of their scientific instruction. It is only in Germany that there still subsist some vestiges of the rights formerly attached to the doctorate. It is true that in consequence of the change which has taken place in the signifcation of the title, and in consequence of the increasing specialisation of the various branches of education, we require of doctors, who wish to instruct, a most searching proof of their profound knowledge of the subjects which they desire to be authorised to profess. For the rest, in most of the German universities, the legal rights of these doctors authorised to instruct, are exactly the same" as those of ordinary professors; in some there are certain restrictions which are of little practical importance. 'The oldest masters, especially the ordinary professors, have no other real advantage than that of having more completely at their disposal the material means of study furnished by the State, and necessary for instruction in certain departments of science; besides, they are legally intrusted with the conduct of the university examinations, and, in fact, the State examinations are of tenest intrusted to them, which naturally exercises a certain influence on the most timorous students. But the influence of examinations is much exaggerated. In consequence of the comeand-go movement of the students, candidates are often tested by examiners whose courses they have never attended.

Of all our university institutions, that of privat-doctnt is what most confounds strangers. They are astonished, not without envying us, at finding among us so many young men disposed to devote themselves to hard scientific work, for the most insignificant fees, without fixed salary and without any assured prospect for the future. And, always from the practical and material point of view, they wonder that the faculties admit so easily, and with such complaisance, these young people who may, at any moment, be transformed from assistants into competitors, and that in a situation so delicate, the employment of annoying methods of competition is so rare and exceptional a thing.

The right of filling vacant chairs, as well as that of giving anthorisation to the privat docenten belong to the faculty, i.e., to the assembly of the ordinary professors, although the former of these rights is not absolute, and the final appeal is not to the faculty. These assemblies are in the midst of the German universities a relic of the ancient colleges of doctors who inherited the privileges of the primitive corporations. They also represent the union of the graduates of old, but much reduced, and organised with the concurrence of the governments. The custom is that for the nomination of the ordinary professors the faculty presents three candidates for the choice of the Govern ment. The latter, it is true, is not rigorously obliged to abide by the candidates presented, but it is extremely rare that the presentations of the faculty have not been respected except at epochs whe party strifes were very hot. Unless for very potent considerations, it is always an extremely weighty responsibility for the representatives of the executive power to institute against the wish of a competent body, a professor who will have to give publicly the proofs of his merit before a numerous auditory.

The members of the faculty have the strongest motives for strengthening as much as possible the teaching body. To be able to give one's self with joy to the labours of the professoriate, the most essential condition is that of being assured that you will not have to speak before too small a num. ber of intelligent auditors. Moreover, the income of many of the professors depends to a large extent on the number of students. Each professor ought, then, to desire that the faculty to which he belongs draws as many and as intelligent students as possible. This end can only be attained if all the masters-professors and prizat docenten-are chosen from among the most distinguished men. On the other hand, the efforts made by a professor to accustom his students to work ener. getically and with intelligence, can only be successful if he is seconded by the other members of the faculty. Finally, the concourse of distinguished colleagues contributes to maintain, in university circles, a more interesting, more instructive, and more active life. To make these reasons yield to other considerations a faculty must already have fallen very low, have lost not only the feeling of its dignity, but also that of the commonest worldly prudence; such a faculty would soon come to ruin.

As to the phantom of a rivalry among the professors, with which it is sought sometimes to frighten public opinion, nothing of the kind can be produced when the teachers and the students are what they ought to be. In the first place, it is only in large universities that there exist two chairs for the same branch of science; and in this case, if there is no difference between the official definition of the two chairs, there is certainly one between the scientific tendencies of the two professors, and these may divide the work in such a way that each reserves the subjects in which he is most competent. Two distinguished professors, who are thus complementary to each other, are so powerful a centre of attraction to students that neither of the two need fear to see the number of his anditory diminish, when even a certain number of the less zealous may divide and follow only one of the two courses.

The injurious effects of rivalry are especially to be feared when one of the professors does not feel himself established in his scientific position. Even this may not exercise any influence upon the decisions of the faculty so long as the case concerns only one or a small number of the voters.

The exclusive domination of one scientific school may be more unfortunate for a faculty than the personal interests of which I have spoken. It may in fact be foreseen that when the school will have had its day, the students will gradually resort to other universities. Years may thus pass, and the faculty be paralysed for a long time,

It is easy to see, under the sway of this system, how many efforts the universities have made to attract to them all the scientific leaders of Germany; for this it is enough to inquire how many men of original genius are found outside the universities. We may have some idea of the result of such an inquiry, for we are rallied on the fact that all German science is a science of professors. If we consider England, we find immediately men like Humphrey Davy, Faraday, Darwin, Grote, who have no connection with the English universities. In Germany, on the contrary, except the savants whom the Government have excluded for religious or political motives, like David Strauss, and except those who, in the quality of members of German academies, have the right of giving lessons in the universities, like Alexander and Wilhelm von Humboldt, Leopold von Buch, \&c., the number of those who are found outside the universities is very small relatively to the number of those who have been professors in them. If we make the same calculation for England, we arrive at an inverse proportion. I have always considered it a very striking thing that the Royal Institution of London, a private society wishing to have for its members and for a distinguished public short courses of lectures on the progress of the natural sciences, has been able permanently to attach to itself for this purpose men having so great a scientific authority as Faraday and Humphrey Davy. There is not here a question of salary; evidently these men were attracted by an auditory composed of men and women of independent spirit. In Germany the universities are incontestably the places of education which always exercise the most powerful attraction for those who wish to instruct. It is clear that this power of attraction arises from the fact that we cannot hope to find elsewhere an audience, not only well prepared, used to work, and capable of enthusiasm, but also disposed to form personal convictions; without a disposition of this kind the science of the master will not bear fruit in the pupil.

Thus is manifest in all the organisation of our universities that respect for the liberty of personal convictions, a respect more profoundly rooted among the Germans than among their Aryan brothers of the Celtic or of the Latin branch. Among these political and practical motives have greater sway. They are always disposed, and this, it appears, in all sincerity, to withdraw from the spirit of research the examination of things which appear to them indisputable as being the foundations of their political, social, and religious organisation; they consider it perfectly legitimate to tell the young people not to cast their eyes beyond the limits which they themselves have agreed not to pass.

When we hold as indisputable a certain order of questions, even when the domain of these questions is out of the way and narrow, even when we have excellent intentions, it becomes necessary to maintain in a determined path those who study, and the master must avoid everything which would disturb authority. Then independent convictions can only be spoken of in a very restricted sense.

You have seen that our predecessors have judged otherwise. If sometimes they have energetically combatted certain results of scientific research, at least they have never attaclied the root of the tree. An idea which did not rest on a personal conviction 
appeared to them to have at bottom no value. In their inmost heart they always guarded the firm persuasion that liberty alone is able to remedy the abuses of liberty, and that a more mature science. would rectify the errors of an incomplete science. The sentiment which urged them to shake off the yoke of the Roman Church is also that under the sway of which the German universities have been organised.

But every institution founded on liberty is obliged to count on the intelligence and judgment of those who use the liberty. Independently of what has been said above on the strbject of the decisions which the students have to take for themselves in what concerns the direction of their studies. and the choice of their masters, the reflections which precede show also the influcnce which they may exercise on the masters themselves. It is a difficult thing to have to continue the course commenced by a colleague, and that difficulty is presented at the ontset of every semester. At every moment the progress of the coure obliges us to fall back upon what has been previously said, to consider the same questions from other points of view and in another order. The master would soon tire of this ungrateful task, if he did not find support in the zeal of his audience. In order to be at the height of his mission, he must feel himself sustained and understood by a sufficient number of intelligent pupils. The flocking of an audience to the lessons of a master has no little influence on his nomination or his advancement; and it has an influence also upon the whole of the teaching body. All this system rests upon the idea that the general current of the opinion of the students cannot long be at fault. The majority among them come to us with a reason sufficiently formed by logic, with a sufficient habit of intellectual effort, witi a judgment so considerably developed by a knowledge of the best models, to be able to discern the truth from a phraseology which has only the appearance of truth. Among students we may already clistin. guish the slite who will be the intellectual guides, of the new generation, and who, in a few years, may perhaps attract the attention of the world. They are those who, especially, in scientific matters, determine the opinion of their comrades; the others involuntarily allow themselves to be guided by them. Naturally, young spirits, inexperienced and impressionable, are liable to fall tmomentarily into error; but, in short, we may be sure that they..will always return soon to just ideas.

Such are, at least, those whom the lyreums have sent to us hitherto. - It would be dangerous for the universities to see arriving in great numbers, students less cultivated. It is necessary that the general spirit of the students should not decline. If that happened, the dangers of academic liberty would surpass its advantages. We ought not then to accuse the univer sities of pride or pedantry, when they admit only with circum spection students educated outside the lycetums, It would be more dangerous still for a foreign pressure to introduce into the faculties masters who would not be fully qualified for having the scientific independence of an academic professor.

Do not forget, then, clear comrades, that you have a great responsibility. This glorious legacy of the past, of which I have already spoken, you have to preserve, not only for our own nation, but also to serve for example to a great portion of humanity. You are bound also to prove that youth is capable of enthusiasm for the independence of convictions and of working for it. I say working. In fact, the independence of convictions does not consist in lightly accepting hypotheses without proofs; it can only be the fruit of experiments and of persevering labours. It is your duty to show that the convic tions, founded on personal researches, are germs most fruitful of new ideas, and furnish better rules of conduct than the direction of the best-intentioned authority. Germany, who, in the sixteenth century was the first to strive for the liberty of convictions, who suffered and was martyred for them, is yet in the van of the fight. A noble mission is allotted to her in the history of the world, and you are called to contribute to its triumph.

\section{REMARKABLE CHANGES IN THE EARTH'S MAGNETISM ${ }^{1}$}

ONE of the most important, scientifically, of the special lectures at the Geographical Society, was that by Capt. Evans, in March last, on the strbject of terrestrial magnetim. The

1 From Lecture at the Royal Ge graphcal Sucety, March it, by Captain F J. Evans, C.B. F.R.S, Hydregraher to the Adnutralty. concluding portion, especially, is of high scientific importance. Capt. Evans gave a historical sketch of the subject of terrestrial magnetism from the time of the discovery of the dip of the magnetic needle. After speaking further on various depart: ments of his subject, Capt. Evans wert on to say :-

"We have now passed in review the successive stages of de velopment of our branch of knowledge, from the pregnant epoch when its principles were enunciated by Gilbert, till the period when the well-directed munificence of his own and other Governments dotted the earth's surface with observatories, and despatched land and sea expeditions, specially equiped, for the deterinination of the magnetic elements. We have seen how, a few earnest and gifted men have, by long and patient analyșis, laid the foundations for future generations to build upon as re gards theory, and unravelled the apparently inextricable web surrounding the needle's daily and yearly movements; tracing these movements to their primary source, the sun : and how by the perseverance of states and of individuals, we are now in possession of accurate knowledge as to the distribution of magnetism over the surface of our globe, as represented by the variation and dip of the needle, and by the measure of the force connected with those component elements. But the task, from a scientific point of view, is far from completed while we remain in ignorance of the causes of greater changes in the earth's magnetism going on from year to year, and so on, possibly through xons of time. From a practical point of view, so far as the interests of men are concerned, the collection of records will be a never ending task, for every generation must observe and chart the magnetic elements of its time.

"The subject of secular" change is thus one of such great interest that the remaining portion of my lecture must be chiefly devoted to it. The active mind of Halley, was drawn, as one of the first, to the probable nature of the causes : collecting such observations of the variation of the compass as had then been made, and projecting them on polar maps, he found that the convergence of the several directions of the needle led to two points in each hemisphere. On this he enunciated the proposi tion 'that the whole globe of the earth is one great magnet, having four magnetical poles or points of attraction; near each pole of the equator two ; and that in those parts of the world which-lie near adjacent to any of these magnetic poles the needle is governed thereby, the nearest pole always being predominant over the more remote' Halley saw, as he confessed with despair, the difficulties attending the proposition, 'as never having heard of a magnet having four poles,' but there were the facts manifested by the earth, and he was too sagacious and sound a philosopher to pass them by. He accordingly propounded a theory which, however fantastic it may now appear, and perhaps did at the time he wrote, has nevertheless within it the fire of genius, and may probably be found yet to contain some sparks of truth. To account for the four poles, and at the same time for the secular change of the variation, he conceived that the earth itself might be a shell, containing within a solid globe, or terella, which rotated independently of the external shell : each globe having its own magnetic axis passing through the common centre; but the two axes inclined to each other and to that of the earth's diurnal rotation. It is not difficult to follow the movements of the consequent four imaginary poles in solu. tion of the problem.

"Hansteen working at the same problem a century after Halley [I $11-19]$, and much on the same lines, came nearly to the same conclusion with regard to the four poles of attraction : and he rendered justice to Halley by recognising him as the first who had discovered the true magnetic attraction of the globe. Han. steen, with the material at his command, went however a step further, and computed both the geographical positions and the probable period of the revolution of this dual system of poles or points of attraction round the terrestrial pole. From these computations he found that the North American point or pole required $\mathbf{I}, 74^{\circ}$ years to complete its grand circle round the terrestrial pole, the Siberian 860 years; the pole in the Antarctic reyions south of Australia, 4,6co years; and a secondary pole near Cape IIorn, I, 304 years. ${ }^{1}$ The influence of these laborious investigations on the minds of subsequent inquirers may easily be imagined.

"The matured view's of Sir Edward Sabine on the secular changes-enunciated in the clearest manner in $1864-72$-are deserving of the highest consideration. An ardent admirer of 